\title{
Tiempo y ficción
}

\section{Time and Fiction}

\author{
Diamela Eltit \\ New York University \\ diamelaeltit@gmail.com
}

\section{Resumen}

Me interesa examinar de una manera parcial —o quizás demasiado general—y, más aún, desde una perspectiva ficcional, el transcurso de agudos dilemas sociales en un conjunto de novelas chilenas escritas a partir del siglo xix para pensar cómo y en cuánto se han modificado los pactos, los lugares, la configuración de las elites y los poderes políticos en el siglo xxi. En realidad, la pregunta que me moviliza es en torno al tiempo y su capacidad de renovación social. O si acaso los tiempos, en los tiempos, mantienen intactas las mismas estructuras de dominación, estructuras que transcurren solapadas, envueltas en nuevos parámetros discursivos.

Palabras clave: Literatura, tiempo, discurso, dominación.

\section{Abstract}

I am interested in examining in a partial way-or perhaps too generally-and, even more, from a fictional perspective, the course of acute social dilemmas in a set of Chilean novels written since the $19^{\text {th }}$ century. I attempt to think how and how much social pacts, places, the configuration of the elites and political powers have been modified in the $21^{\text {st }}$ century. In fact, the main question of this essay is temporality and its capacity for social renewal. Or whether certain temporalities keep the same structures of domination overlapped, overlapped or wrapped in new discursive parameters.

Keywords: Literature, temporality, discourse, domination. 
El trabajo con los signos, las imágenes que los signos construyen, son patrimonios en los que se funda la literatura. Signos e imágenes que emanan del aparato social, signos e imágenes siempre en movimiento al igual que el devenir lingüístico que los generan. El tiempo y los signos, la historia del tiempo y los signos, pueden ser leídos desde la literatura, para examinar allí cómo se representan las épocas y sus mandatos, las crisis y los campos de sentido abiertos por el sistema social.

La irreductible literatura se acerca, se distancia, habita, lee, genera escenarios siempre sociales, acotados o distorsionados en los que transcurren los hilos en los que se tejen los sistemas. La literatura proyecta y atraviesa su tiempo, lo retrocede, lo burla, lo descifra, lo presagia.

No es posible pensar una literatura ausente de signos y síntomas siempre políticos, entendiendo lo político como una forma múltiple donde, desde el lenguaje, se producen las visiones y versiones posibles en las que se organiza el acto de vivir. Digo vivir como una tarea siempre completa e incompleta a la vez.

Me interesa examinar de una manera parcial —o quizás demasiado general- $y$, más aún, desde una perspectiva ficcional, el transcurso de agudos dilemas sociales en un conjunto de novelas chilenas escritas a partir del siglo xIX para pensar cómo y en cuánto se han modificado los pactos, los lugares, la configuración de las elites y los poderes políticos en el siglo xxI. En realidad, la pregunta que me moviliza es en torno al tiempo y su capacidad de renovación social. O si acaso los tiempos, en los tiempos, mantienen intactas las mismas estructuras de dominación, estructuras que transcurren solapadas, envueltas en nuevos parámetros discursivos. Máscaras de sí.

Atravesando técnicas y tecnologías, usos y costumbres, me interesa leer los movimientos que concentran poder, dominación y apropiaciones específicas de cada periodo. Lo que me convoca es revisitar esas obras canónigas para pensar conexiones, metáforas, encadenamientos y zonas petrificadas.

La novela Martín Rivas se constituyó en el texto poscolonial más recurrente para establecer la línea de tiempo fundante que organiza el canon nacional. Porta la condición de "lectura obligatoria" en los estudios literarios porque el orden cuidadosamente trazado que propone la novela permite pensar la arquitectura de la reciente "independencia", cruzada por fuerzas divergentes provenientes de la Colonia, enfrentadas a las construcciones de la reciente nación liderada por una acotada elite criolla.

Pero, lo que me parece crucial es detenerme en uno de los pilares que sostiene el texto y que radica en la formación y formalización de una alianza productiva entre la alta burguesía propietaria y la clase media ilustrada. La unión entre ambos sectores se realiza en los momentos en que se produce un vaivén entre el modelo latifundista y la emergencia y desplazamiento del modelo inversionista generado por la revolución industrial. Y, a partir de la figura del propietario, es posible comprobar el modo en que ingresa la propiedad individual al Estado mediante la captura del poder político que les permite controlar los ejes públicos-privados. 
El personaje Martín Rivas, provinciano, pone en evidencia la tensión entre centro y periferia, pero más allá de su procedencia territorial, encarna esa figura de la clase media que porta un saber - estudios de leyes - que le permiten "escalar" socialmente, pues esa formación académica le garantiza al burgués propietario, Dámaso, contar con un fiel y eficaz administrador de sus bienes. Así, el letrado será el encargado de acrecentar y administrar su riqueza familiar. La unión más sólida (la familia) está garantizada por el matrimonio de Martín Rivas con Leonor, la hija de Dámaso. Martín Rivas debe atravesar una serie de obstáculos para acceder a Leonor, pero las diversas situaciones pueden ser leídas como aquella tarea que le es propia por encarnar a una clase media sin fortuna. Pero, finalmente, la boda se materializa en una unión que le permite al propietario, Dámaso, cumplir con otro de sus objetivos: iniciar una carrera política en el Parlamento, después de concretar a través de su yerno una provechosa administración de sus bienes.

Así, el provinciano Martín Rivas ingresa a la elite para forjar los signos de una alianza donde el matrimonio interclase, posibilitado por el acceso a la mujer burguesa, opera como una mera fórmula para extender el poder del propietario e integrar al letrado de la clase media para formar con él una sociedad rentable. En ese sentido, Leonor, la futura esposa, es un medio, apenas un dispositivo para garantizar la acumulación de poder entre los hombres.

Martín Rivas muestra, en principio (solo en principio) una diversidad de problemáticas, matices domésticos, las tensiones y formas de organización de la sociedad poscolonial del siglo XIx. Publicada en 1862 por Alberto Blest Gana, de filiación liberal, textualiza cada uno de los lugares asignados a los cuerpos. De hecho, su autor, muy reconocido en su tiempo, diplomático, escritor de ensayos y crítico literario, señaló: "Juré ser novelista y abandonar el campo literario si las fuerzas no me alcanzaban para hacer algo que no fuesen triviales y pasajeras composiciones".

Efectivamente, no escribió una composición trivial, sino que se abocó a textualizar, desde su posición social y letrada, las formas en que se cursaban los dilemas de las elites formadas por la gran burguesía criolla; pero la pregunta más candente es si la estructura de la propiedad burguesa se ha modificado o en cuánto se ha modificado. Interrogarse si existe hoy, en pleno siglo xxi, un tránsito de lo privado a lo público para configurar así una forma de poder totalizante mediante la captura del Estado como espacio final de control. Y de qué manera la clase media ilustrada se alía con la alta burguesía para administrar y acrecentar bienes y poder.

La novela Martín Rivas es considerada fundacional en el mapa literario chileno $y$, en ese sentido, su importancia descansa en la formación de un canon mediante un texto romántico-realista, pero desde otra perspectiva es posible leer en ella las estructuras de dominación y los pactos para pensar cómo se genera la extensión de un control social. Allí la mujer burguesa, destinada al matrimonio, opera como un mero objeto para garantizar la producción y reproducción del poder.

La puesta en marcha de la novela chilena que concentró los dilemas de las elites de su tiempo a mediados del siglo XIX, me parece contingente en pleno siglo XXI. 
Desde una mirada política puede ser leída como presente, y acaso futuro más allá del capitalismo globalizado (inédito en su dimensión) que es el que hoy experimentamos. Muestra y demuestra el desplazamiento sincronizado entre cuerpos y riqueza de acuerdo a nuevos mapas productivos y, de manera relevante, es posible confirmar cómo la riqueza ingresa al aparato estatal mediante cargos de representación que permiten, precisamente, facilitar desde el Estado, o con el Estado, la acumulación de capital.

Desde mi perspectiva, esta novela es crucial para entender la matriz social en la que habitamos y los movimientos siempre exactos de esta matriz. Más allá o más acá de los detalles epocales, las figuras centrales mantienen idéntico protagonismo en la esfera social más literal del presente. $\mathrm{O}$, dicho de otra manera, la obra conserva su filiación ultrarrealista que permite entender las operaciones políticas practicadas por una élite para mantener su dominio social, fundado en un articulado cruce entre lo público y lo privado mediante la colaboración siempre oportuna de la clase media ilustrada. Y allí la mujer burguesa operando como un simple engranaje posibilitador.

En otro registro, en un registro más tenso, me interesa pensar aquí el “abajo” planteado en el libro de relatos Subterra, publicado en 1904 por Baldomero Lillo. Desde luego el conjunto de cuentos recoge las formas en que se cursa la industrialización minera del carbón de su tiempo, en medio de la pobreza que origina cuerpos y destinos unívocamente trágicos. Subterra es uno de los libros más importantes de la literatura social chilena en la medida que ilumina universos humanos signados por la explotación (que trabajó de manera infatigable Carlos Marx). El libro se detiene en una forma de trabajo exenta de derechos y carente de horizonte como no sea la simple sobrevida afectada por una biología débil (la silicosis) o por las malas condiciones laborales (el derrumbe).

Me resulta importante encontrar una forma de leer esa "subterra" hoy. Me refiero a cuerpos trabajadores que habitan "abajo" o en el subsuelo de las normativas y fuera del escenario social construido y dictaminado por la hegemonía. Cuerpos multitudinarios que se desplazan ahora mismo por zonas abismales del sistema, expulsados de cualquier legalidad porque, precisamente, el neoliberalismo actual consiguió destruir - en gran medida - los acuerdos acerca de las condiciones del trabajo, retrocediendo en forma impactante casi un siglo de luchas por derechos laborales. Tal como los poseedores de las antiguas minas "daban" trabajo en paupérrimas condiciones económicas y sanitarias, hoy el empresariado local es el que lo "da", según aseguran economistas, políticos y los mismos empresarios, porque se entiende el trabajo en tanto dádiva o regalo, y ese "regalo" justifica salarios inconsistentes para la gran población trabajadora.

Por otra parte, los migrantes, los pobres, se lanzan a las calles para tener un sustento posible mediante la venta ambulante. Lo hacen sin cobertura, ganando día a 
día, su día, asediados por la policía y sometidos a las inclemencias del tiempo. La mala alimentación, la pobreza y hasta la miseria que consiguió configurar Baldomero Lillo están hoy intactas en los espacios silenciados por el poder, segregados, hacinados en sectores normados como espacios de exclusión, zonas tan invisibles y silentes como un socavón minero.

Pero, en otro registro ficcional, puede ser oportuno pensar en la figura marxista de "el viejo topo" que está en movimiento en el subsuelo de la historia y puede emerger para cambiar el curso opresor. "El viejo topo" es una imagen que emerge de Hamlet, de William Shakespeare, retomada por Hegel y más adelante por Marx, para fijarla en un derrotero de cambio político.

Si se lee "performáticamente" el 18 de octubre del año 2019, fecha de inicio de una revolución chilena inesperada, se puede pensar en un tipo de subterra, en (jóvenesviejos) topos que emergieron desde el subsuelo (de la historia) encarnados en las y los estudiantes secundarios y su a-salto al metro para darle sentido y visibilidad a ese espacio sumergido.

Una emergencia que, de acuerdo a los planteamientos de Jacques Rancière en su libro El desacuerdo, puso en la esfera pública "a la parte de los que no tenían parte" en la trama hegemónica y, de esa manera, socavaron la rigidez política que desde diversas trincheras partidistas se habían volcado solo a administrar el modelo. Ese "viejo topo" hizo política en la medida en que visibilizó cuerpos carentes de discursos, expulsados del deseo social, expropiados de cualquier atisbo de subjetividad. Fue ese "viejo topo" el que salió a la superficie para dar inicio así a un tiempo político gestado por una ciudadanía multitudinaria que esgrimió su poder y su subjetividad. Cuerpos que fueron tachados de manera exacta como "alienígenas" escenificando así una expresión posible ante un desconocimiento social por parte de las elites. Cuerpos locales carentes de relato, habitantes, para los propietarios del capital, de otro u otros “planetas". Ingresó entonces esa parte de los que no tenían parte, operando así desde los relatos de Baldomero Lillo subterráneos, una "restauración” de esos cuerpos considerados solo como anónimos consumidores de baja intensidad por la burguesía.

Entonces, pensando de manera paradójica, existe hoy un subterra "invisible" para las elites, vidas expuestas al trabajo robótico, extenuante, donde la existencia se cursa solo desde el umbral del consumo y la deuda para seguir vivos. Una vez más me parece necesario señalar que epistemológicamente la palabra deuda proviene de "debita" que significa "tener sin tener". En ese sentido, desde una perspectiva radical, me parece que los cuerpos le pertenecen al sistema crediticio que dispone como condición del propio cuerpo de los deudores. Los salarios débiles recuerdan las "fichas-salitre" porque el modelo se traga ese salario mediante el canal abierto hacia el próximo pago que ya está consumido o consumado por la deuda que inocula el sistema.

Pero, existe otro subterra (el 18 de octubre del 2019) que emergió y puede reemerger y reemerger a la manera del topo buscando quebrar la condición histórica 
para formar parte precisamente de la historia que lo niega. Por ahora, Subterra de Baldomero Lillo continúa, sin tregua alguna, mostrando la inexistencia, la enfermedad, la muerte.

Y examinando los matrices de la literatura chilena en el tiempo, su recurrencia, su oscilación, su inamovilidad, sigo pensando en cómo se configuró el sujeto mujer en la novela Juana Lucero, una obra que habita el canon y que forma parte de la llamada "literatura social", escrita por Augusto d'Halmar y publicada en 1902.

La novela muestra la vertiginosa caída social de su protagonista, Juana, hija de una costurera soltera. El texto la describe con su madre, pero ella muere y Juana enfrenta la orfandad hasta llegar a la prostitución y a la locura. El fatalismo se deja caer sobre Juana Lucero, que transita como objeto devaluado por un sistema que la castiga social y físicamente de manera implacable. El texto parece preescrito o proscrito por un sistema que actúa de manera lineal sobre la mujer que carece de "redes" (ocupando un término actual) y expuesta a un abierto desamparo que la empuja a una circulación por las superficies como un mero objeto sexual.

Pero también, siguiendo los dictámenes de su tiempo, la madre con su soltería porta un estigma que se traspasa a la hija y la condena por su nacimiento "impuro". O la falta de un padre proveedor la empuja al cataclismo. En ese sentido el texto repite un libreto social que acecha a la mujer pobre sin oficio, como es el camino a la prostitución. $\mathrm{O}$, desandando el camino, se puede leer en la obra cómo se genera una prostituta a partir de las condiciones adversas que la rodean.

Juana Lucero fue leída desde el naturalismo y se reconoció en la obra la influencia de Émile Zola. La pobreza como un "destino" siempre trágico, irreversible, maléfico, habitó el umbral del siglo xx para denunciar los costos de la industrialización y, allí, la mujer quedó liberada a la desgracia de su origen y de su transcurso.

Augusto d'Halmar consiguió pensar a la mujer pobre o relativamente pobre (la madre de Juana era costurera) y le asignó un derrotero. La novela tuvo sentido en su tiempo y le otorgó valor literario. Desde luego, más allá de las variables temporales, la pregunta más candente es si es posible leer hoy la condición de la mujer pobre, desafiliada de redes familiares sólidas, bajo un prisma tan trágico y tan violento como el que encarna la novela.

Si se piensa desde este preciso presente el transcurso pobre como un destino que empuja a los cuerpos de las mujeres a una forma de determinismo, es evidente, más allá o más acá de la prostitución como oficio, que la mujer pobre está expuesta a violencias permanentes. Juana Lucero se repite de manera recurrente en diversos espacios y especialmente en niñas recluidas en instituciones - tercerizadas por el Estado- que no contienen (como el SENAME) o van a la muerte en medio de una vida de abusos extremos, como fue el drama que culminó con el asesinato de la adolescente 
Ámbar Cornejo. En suma, existe una maquinaria destructiva en una parte consistente del universo masculino perfectamente sincronizada, que autoriza, ejecuta y repite.

Después de más de un siglo, la asimetría de género conserva intacta la vulneración principalmente de los cuerpos pequeños o adolescentes como un signo inequívoco de un poder y hasta un derecho que se ejerce de manera sistemática. Doble o triple uso y abuso en aquellas zonas marcadas por la carencia que dan origen a la más absoluta inexistencia.

La novela de d'Halmar fundada en la violencia sexual y en la objetualización del cuerpo nunca ha cesado de transcurrir de manera mecánica, como una mera cifra social, naturalizada, y repetida y aceptada por el transcurso cómodo de una sociedad desigual. Las mujeres, las desiguales en la desigualdad $-\mathrm{y}$ particularmente las mujeres pobres - son el "costo" asumido pero a su vez estigmatizado por el mismo sistema que lo produce.

Más allá de la recurrencia de la Juana Lucero en el hoy, me parece necesario pensar otra obra, también iniciática, la novela María Rosa, Flor de Quillén de Marta Brunet, publicada en 1927, que aborda la violencia emocional oculta en la figura del don Juan. Esta figura emerge en la obra El Burlador de Sevilla de Tirso de Molina publicada en 1630. Y repensada en 1884 por José Zorrilla como Don Juan Tenorio.

Este personaje se desplazó desde la literatura hasta inscribirse como nombre en las vidas cotidianas para señalar al hombre dedicado a la seducción de mujeres. Marta Brunet se funda parcialmente en la figura literaria para buscar allí una nueva versión deconstructiva del personaje del don Juan mediante una forma de emancipación de la protagonista Rosa María. Como señala Jacques Rancière, la mujer en esta obra modifica el campo de lo posible y de lo pensable y consigue dar un vuelco a la situación que la envuelve. A diferencia de Juana Lucero, ella huye de la victimización y encuentra estrategias para modificar lo que podría haber sido un "destino" negativo.

Rosa María, la joven mujer casada con un hombre mayor y respetada por su comunidad es requerido por Pancho, un campesino seductor de mujeres. Él apuesta con los hombres del pueblo que la seducirá. Empieza su trabajo amoroso y efectivamente Rosa María se acerca a Pancho y se produce el encuentro sexual. Los hombres del pueblo están afuera esperando la salida del organizador de la apuesta, pero Rosa María lo percibe y entiende que ha sido víctima de un engaño y revierte la situación. Ante la certeza del espionaje del que es víctima, grita y acusa a Pancho de intentar atacarla sexualmente, Pancho sale humillado de la casa y los amigos se ríen ante su fracaso.

Esta novela de Marta Brunet abre para su protagonista un horizonte inesperado. El amor como "atributo" femenino es descartado. Rosa María decide no sufrir y opta por defenderse de la violencia emocional a la que ha sido sometida, y para eso usa "las tretas del débil" (o de la débil) - como diría la crítica literaria argentina Josefina Ludmer- y da vuelta la situación.

Así, en 1927, Marta Brunet abordó esa forma de traición para conseguir relaciones sexuales, pero el giro de esa escritura radica en la renuncia al sentimentalismo 
con el que ha sido caracterizado el sujeto femenino y el despliegue de estrategias de protección y salvataje. María Rosa, la protagonista, es infiel, pero esa infidelidad no la condena porque sencillamente es obviada por la protagonista y, siguiendo a la obra literaria, el "burlador" resulta burlado.

Es la mujer que repiensa su cuerpo como mero objeto y objetivo para el deseo masculino lo que la obra aborda. Politiza su cuerpo y busca preservarse y salir airosa de una situación peligrosa que inevitablemente la iba a menoscabar. Pienso que hoy esos dos cuerpos - Juana Lucero y Rosa María Flor de Quillén- circulan por las superficies sociales del siglo xxi de manera multitudinaria. Me parece que los paros universitarios, realizados ante las diversas formas de abuso por las jóvenes feministas universitarias del año 2018, pusieron de manifiesto el cuerpo como una zona política y no como un botín para el deseo masculino. Se produjo así una emancipación liberadora que generó asambleas, hablas, discusiones.

Desde luego la desigualdad de género hoy, en el siglo XxI, persiste en cada uno de los ámbitos de la vida de las mujeres. La literatura de Augusto d'Halmar y de Marta Brunet las pensaron de manera diversa, pero son completamente reconocibles en el hoy, a pesar de las diferencias temporales.

Pensar el siglo XXI implica pensar el siglo xIX y el xx. Significa volverse contemporáneos de ese tiempo, de esos personajes que transitan hoy un presente regido por las mismas alianzas elitistas de las que dio cuenta Martín Rivas, y la pobreza subterra y la desigualdad dramática de Juana y María Rosa.

El tiempo, en una de las lecturas posibles, es una ficción completa.

\section{Referencias}

Blest Gana, Alberto. Martín Rivas. Santiago de Chile, Zig-Zag, 1900.

Brunet, Marta. María Rosa, Flor de Quillén. Santiago de Chile, La Novela Nueva, 1929.

De Molina, Tirso. El Burlador de Sevilla. Sevilla, Padrino, 1690.

D’Halmar, Augusto. Juana Lucero. Santiago, Editorial Universitaria, 1989.

Lillo, Baldomero. Subterra. Santiago de Chile, Imprenta Universitaria, 1907.

Rancière, Jacques. El desacuerdo. Buenos Aires, Nueva Visión, 1996.

Shakespeare, William. Hamlet. Cambridge, Cambridge University Press, 1948.

Zorrilla, Juan. Don Juan Tenorio. Madrid, Yenes, 1846.

Enviado: $1^{\circ}$ de octubre de 2020

Aceptado: 10 de diciembre de 2020 